NOTAS

\title{
"Esto lo estoy tocando mañana": poética del tiempo y de la eternidad en El perseguidor, de Julio Cortázar
}

\author{
"Esto lo estoy tocando mańana": \\ poetics of the time and the eternity in El perseguidor \\ by Julio Cortázar
}

\author{
BLANCA SANTOS ${ }^{a}$ \\ ${ }^{a}$ Westfälische Wilhelms-Universität Münster, Alemania. \\ Correo electrónico: blanca.santos1710@gmail.com
}

Este trabajo analiza los mecanismos narrativos que utiliza Julio Cortázar para plantear una poética del tiempo absoluto en El perseguidor. Nos centramos particularmente en el análisis de la construcción del protagonista y en la formulación de la búsqueda como secreto, siguiendo las ideas poéticas de Ricardo Piglia a propósito de la novela corta.

Palabras clave: tiempo, jazz, bebop, personaje, absoluto, eternidad.

This paper analyzes the narrative devices that Julio Cortázar used to propose a poetic of the absolute time in Elperseguidor. I focused particularly in the analysis of the protagonist construction and in the persecution as secret, following the ideas of Ricardo Piglia about the nouvelle.

Key words: time, jazz, bebop, character, absolute, eternity. 
Dentro del ámbito hispánico existen algunos casos reseñables de escritores que se han preocupado por trasponer el hecho musical a su literatura, si bien la crítica ha señalado que suponen excepciones aisladas ${ }^{1}$. Quizá los autores más conocidos que han conseguido aunar lo literario y lo musical sean Alejo Carpentier y Federico García Lorca; sin embargo, la mayor acumulación de escritores con inclinaciones y gustos musicales se dio en el área del Río de la Plata, a mediados del siglo xx. En esta región, como indica Matamoros (25), germinó "un contacto literario-musical muy sugestivo", con "escritores que son músicos, como Felisberto Hernández, Juan Rodolfo Wilcock y Daniel Devoto, o aficionados a la música como Julio Cortázar, Eduardo Jonquières y Jorge Bosco". El caso de Cortázar es conocido por la fascinación que el argentino sentía por el jazz, una fascinación que plasmó en numerosos lugares de su literatura (Goialde Palacios 483-496) y que alcanzó su formulación más profunda en El perseguidor, relato incluido en Las armas secretas (1959), en el que utiliza como materia la figura del saxofonista Charlie Parker, fallecido trágicamente pocos años antes, en 1955.

$\mathrm{Si}$ bien $E l$ perseguidor es un relato ampliamente abordado por la crítica desde múltiples perspectivas, considero que todavía es posible arrojar algo de luz sobre la construcción de su protagonista (Johnny Carter, alter ego de Parker), y sobre el que quizá sea el motivo principal del texto: el tiempo. Para ello, partiremos de los conceptos de personaje y secreto, dos nociones aludidas por Ricardo Piglia en sus ideas poéticas sobre la nouvelle o novela corta, género que es posiblemente el más adecuado a la hora de definir la narración (frente a la categoría cuento, utilizada en otras ocasiones por la crítica). ${ }^{2}$ Por un lado, indica Piglia que la noción de trama está estrechamente ligada al cuento mientras que la noción de personaje se relaciona generalmente con la forma novela (2014); ${ }^{3}$ por otro, mientras que el concepto de enigma opera comúnmente en el cuento, el de secreto lo hace en la nouvelle (2006: 145-146). Si tenemos en cuenta la presencia del personaje mítico y de la búsqueda constante del absoluto que lleva a cabo Johnny como 'secreto' podremos entender mejor la singularidad de la obra frente al resto de relatos incluidos en Las armas secretas, con los que además difiere notablemente en extensión. ${ }^{4}$ Por decirlo utilizando el símil cortazariano, $E l$ perseguidor gana a los lectores por puntos, no por nocaut.

Existen en el texto dos características que, por su uso extraordinario, llaman la atención sobre las demás: el narrador escogido y los tiempos verbales utilizados. El punto de vista del relato es el de Bruno, crítico musical convertido no solamente en el biógrafo

\footnotetext{
${ }^{1}$ Así lo indican, entre otros, Matamoros (2002: 25), Garí Barceló (2012: 74) y Piqueras Flores (2020: 17).

2 José Manuel Oviedo se pregunta: “¿son cuentos tanto ‘El perseguidor’ de Cortázar, que tiene más de cincuenta páginas, como 'El dinosaurio' de Monterroso, que consiste en una línea?” (43). Entre otros, Susana Jakfalvi, la editora de Las armas secretas en Cátedra (47), conviene en llamarlo nouvelle. Stassinos habla de "cuento largo (o novela corta)".

${ }^{3}$ Consultado por la edición electrónica de Formas breves, sin paginar.

${ }^{4}$ Sus más de 20.000 palabras suponen más del doble de extensión que "Los buenos servicios" (el siguiente texto más largo) o casi el cuádruple que "Las babas del diablo".
} 
de Johnny sino también en su amigo, y que por su configuración representa lo opuesto al saxofonista, incapaz de romper con un mundo rutinario aparentemente cómodo: "Ya a lo mejor es por eso que Johnny me toca la cara con los dedos y me hace sentir tan infeliz, tan transparente, tan poca cosa con mi buena salud, mi casa, mi mujer, mi prestigio. Mi prestigio, sobre todo. Sobre todo mi prestigio" (2007: 177). Bruno, como narrador y a la vez personaje recoge toda la "información segmentada para presentar al narratario, de una manera amplia y detallada, al personaje de su interés, Johnny Carter, debidamente construido desde una pluralidad de voces" (Chacón 42). En cuanto a la temporalidad del relato, Cortázar, por boca de Bruno, toma como base un pretérito perfecto compuesto que va mutando a lo largo de la narración, hasta llegar a utilizar un sorprendente futuro que transfiere a la sintaxis la elasticidad cronológica sobre la que gravita El perseguidor. ${ }^{5}$

Desde el comienzo, Bruno da cuenta de la situación miserable de Johnny, adicto, enfermo y sin saxofón, con una desnudez que es literal pero que también simboliza su desconexión con las normas que rigen la sociedad en la que vive. Su situación no lo convierte en un genio (2007: 176), pero refleja las ataduras a las que está sujeto el resto del mundo, representado en Bruno: el "tú no haces más que contar el tiempo" (2007: 142) que le espeta el saxofonista abre la primera conversación entre ambos. La preocupación por el tiempo, presente a lo largo de la literatura de Cortázar (Park), va a ser el tema de obsesión de Carter. Esta preocupación va a ir asociada a la imagen del viaje en metro, el lugar de la evasión donde se produce la pérdida del saxofón, y en el que el tiempo entre una parada y otra puede elongarse gracias al pensamiento humano. El metro presenta por primera vez la oposición entre el tiempo medible y el tiempo percibido - “apenas un minuto y medio" frente al "buen cuarto de hora" (2007: 153). El viaje, como la música, supone un efectivo modo de evasión de lo cotidiano, narrado a partir de los recuerdos de infancia de Carter, en los que Cortázar utiliza simbólicamente la preocupación de sus padres por "hipoteca" (2007: 17), término que, más allá de remitir a los problemas económicos, hace referencia también a las obligaciones que se contraen a lo largo de un tiempo en la sociedad contemporánea, y que impiden el desarrollo de una verdadera libertad.

Bruno, tomando la voz narrativa, nos va a introducir también en la problemática de la temporalidad, pero siempre focalizando su discurso en la figura de Johnny. De esta manera, nos encontramos con una referencia a una de las claves de la poética de Cortázar, la ruptura de la gran costumbre: "pero la costra de la costumbre se rajó en millones de pedazos" (2007: 158). Frente al tiempo cotidiano de su vida miserable y prosaica, para Johnny el tiempo de la música es el tiempo de la felicidad, ya que mediante ella logra el absoluto temporal: "Yo me di cuenta cuando empecé a tocar que entraba en un ascensor, pero era un ascensor de tiempo" (2007: 149); "Si yo pudiera solamente vivir como en esos momentos, o como cuando estoy tocando y también el tiempo cambia" (2007: 154).

Si los recuerdos que sobrevienen en el metro y la música son las dos formas de evasión presentadas en la primera conversación, existe un tercer elemento que sobrevuela

${ }^{5}$ Véanse al respecto los trabajos de Cifo González y Stassinos. 
el relato y que Cortázar dosifica a lo largo de las páginas, sin llegar a descubrirlo del todo, el uso de las drogas: "probablemente también en esa época la marquesa empezó a acostarse de cuando en cuando con Johnny, y fumar con él" (2007: 159). Lejos de la idealización del pasado, la tensión se da con un presente dominado por el consumo de marihuana. Carter jura, en su primera alusión, que "ese día [el del viaje en metro] no había fumado ni un pedacito, ni una hojita" (2007: 153). Música, recuerdos y droga son los instrumentos de búsqueda de ese tiempo absoluto, pero son incompatibles, como bien nos hace ver el narrador, preocupado porque Johnny no fume marihuana. En este sentido, la recuperación del saxofón perdido es el único medio que tiene Bruno de acercarle a la música y alejarle de la droga, por eso la música y la droga en Johnny son dos fuerzas que se destruyen una a otra: "Por nada del mundo tiene que fumar antes del primer concierto" (2007: 157). Ahora bien, existe una adicción más fuerte, que sobrevuela el relato de manera implícita: la de la heroína, la sustancia más peligrosa que acompañó a Charlie Parker a lo largo de los últimos años de su vida. ${ }^{6}$ Cortázar no alude directamente al consumo de esta potente droga, haciendo al cannabis culpable de la lamentable situación de Johnny Carter. Inverosímilmente, es la marihuana la que le lleva incluso a someterse a una desintoxicación; sin embargo, una mención a "la piel de los muslos con unas manchas raras que me han dado un asco infinito" hacen pensar en las heridas producidas por las inyecciones de heroína. El escritor oculta así, como secreto, el alcance completo de la desgraciada situación de Charlie Parker.

El consumo de droga conecta trágicamente la biografía de Parker-Carter con un autor presente en El perseguidor desde el paratexto inicial: el poeta Dylan Tomas, "a quien Johnny lee todo el tiempo" (2007: 159). No por casualidad, también para Thomas el tiempo se configura como una obsesión que recorre su poética. Así, en "The force that through the green fuse drives the flower" el poeta estadounidense escribe: "And I am dumb to tell a weather's wind / how time has ticked a heaven round the stars" (Thomas 30). Al respecto, indica Esteban Pujals:

Es muy frecuente para Dylan Thomas [...] observar el mundo en una forma actual y abarcar de un solo golpe de vista lo pasado, lo presente y lo futuro, y hacerlo revivir con tremendo impulso de su originalísima imaginación. Y la visión del poeta, lo que podríamos decir su mensaje, se efectúa de un modo nuevo y espontáneo, manifestándose polifónicamente y produciendo la sensación de que se presenta simultáneamente en distintos planos. (23)

Si en la obra de Dylan Thomas el tiempo poético es el tiempo eterno, hay en la imagen de Carter dibujada por Cortázar una búsqueda extraordinaria de esa eternidad: una persecución que da título al relato y que se presenta a Bruno como una revelación a partir

\footnotetext{
${ }^{6}$ Indica Borello que "Charlie lo probó todo [...]. Durante casi toda su vida [...] estuvo dominado por la necesidad cotidiana de la heroína, la peor de todas las drogas. Y por conseguirla llegó hasta a firmar un contrato por el cual entregaba a un vendedor la mitad de todas las entradas por grabaciones... Empeñaba sus ropas, siempre su saxo" (585).
} 
de la grabación de Amorous, tan deficiente como extraordinaria: "ha sido necesario escuchar esto [...] para que yo me diera cuenta de que Johnny no es una víctima, no es un perseguido como cree todo el mundo, como yo mismo lo he dado entender en mi biografía [...]. Ahora sé que Johnny persigue en vez de ser perseguido" (2007: 179). Como la poesía de Thomas, el frenético bebop se convierte en un medio para alcanzar el ideal de lo absoluto a través de la experiencia artística. De esta manera, Bruno nos dirá que "hay en Johnny algo del otro mundo" (2007: 177) y que mediante la música Johnny puede "estar en otro lado" (2007: 180). La idea de trascendencia que está construyendo Cortázar a través de la música creada por Carter se conecta a la eternidad de tiempo estático y detenido, que se vincula con una simbología cristiana y hasta crística. ${ }^{7}$ En ella, la labor de Bruno, como biógrafo, equivale a la de un evangelista, que termina utilizando su escritura sobre Johnny para hablar de sí mismo: "Lo malo es que si sigo así voy a acabar escribiendo más sobre mí mismo que sobre Johnny. Empiezo a parecerme a un evangelista y no me hace gracia [...]. ¿Qué clase de evangelista soy?" (2007: 181-182). Sin embargo, esta pulsión religiosa implica a su vez una negación de la deidad sobrenatural:

- Sobre todo no acepto a tu Dios- murmura Johnny-. No me vengas con eso, no lo permite. Y si realmente está del otro lado de la puerta, maldito si me importa. No tiene ningún mérito pasar al otro lado porque él te abra la puerta. Desfondarla a patadas, eso sí. Romperla a puñetazos, eyacular contra la puerta, mear un día entero contra la puerta. Aquella vez en Nueva York yo creo que abrí la puerta con mi música, hasta que tuve que parar y entonces el maldito me la cerró en la cara nada más que porque no le he rezado nunca, porque no quiero saber nada con ese portero de librea, ese abridor de puertas a cambio de una propina, ese... (2007: 201).

Como indica Coulson, la naturaleza de Carter lo asemeja en cambio a un nuevo Orfeo, tal y como aparece en el propio relato: "Nadie sabe ya cuántos instrumentos lleva perdidos, empeñados o rotos. $\mathrm{Y}$ en todos ellos tocaba como yo creo que solamente un dios puede tocar un saxo alto, suponiendo que hayan renunciado a las liras y a las flautas" (2007: 143-144). En este sentido, Johnny emprende una búsqueda, una persecución a través de su saxo y del bebop, una música de jazz que "desecha todo erotismo fácil" (2007: 167) de formas como el blues y crea una música que a Bruno le "gustaría poder llamar metafísica [...], una construcción infinita cuyo placer no está en el remate sino en una reiteración exploradora, en el empleo de facultades que dejan atrás lo prontamente humano sin perder la humanidad" (2007: 167). Si, en general, el jazz es la música basada en la improvisación, con un swing particular que implica una libertad rítmica característica que Cortázar compara

\footnotetext{
${ }^{7}$ Véase al respecto el trabajo de Fiddian. Si Cortázar dedica el relato a Ch. P., utilizando las iniciales del músico, hemos de notar entonces la simbología de las iniciales escogidas para el nombre del protagonista: Johnny Carter no solamente se asemeja por sonoridad a Charlie Parker, ni tampoco es solo una creación a partir de otros dos saxos altos de los cuarenta — Johnny Hodges y Benny Carter (Borello 574) — sino que sus iniciales coinciden, por un lado, con las de Jesucristo (Coulson 111), y por otro, con las del mismo escritor.
} 
con el surrealismo por su capacidad de romper la puerta de lo racional, ${ }^{8}$ el bebop de Dizzy Gillespie, Thelonious Monk y, sobre todo, de Charlie Parker se opone a cualquier acomodo de ese swing, con una estética cortante, de una potencia desmesurada. El escritor argentino transforma esta música en el relato en una experiencia vital agónica, que conduce a Johnny irremediablemente a su muerte. También en este aspecto de nuevo se aúnan forma y sentido para que la voz narrativa de Bruno sea quien actúe a modo de coro griego y nos anticipe el fatum implacable: "quizá acabaría en lo peor, en la locura completa, en la muerte, pero no sin haber tocado a fondo lo que busca en sus tristes monólogos a posteriori, en sus recuentos de experiencias" (162).

Además, el biógrafo nos da la clave de otro de los elementos a los que Johnny se aferra para detener el tiempo y escapar de la realidad: las conversaciones con Bruno. Por eso, cuando Johnny no puede asirse a su amigo mediante el diálogo sucede la desgracia: “QQué otra cosa podía hacer sino ir en seguida a verlo? Pero de todos modos lo he dejado para mañana. Y a la mañana siguiente me he encontrado a Johnny en las noticias de policía de Figaro, porque durante la noche parece que Johnny ha incendiado la pieza del hotel" (2007: 170). El perseguidor se configura como una serie de cuadros conversacionales entre Carter y su biógrafo en los que las palabras de Johnny son el sostén de todo el relato. No se trata solo de una cuestión temática, sino que toda la nouvelle está construida formalmente en torno a este eje, fragmentario por definición. El mismo Bruno nos lo hará ver cuando haga referencia a unas "secuencias. No sé decirlo mejor" (2007: 183). Cortázar está plasmando con ello, de nuevo, uno de los recursos principales de su poética, la idea del coágulo (1978: 72) que consigue romper esa costra de la gran costumbre. Así, estas conversaciones se introducen dentro del relato como apariciones en la prosaica realidad de Bruno, abocetada en un matrimonio monótono, ${ }^{9}$ y en la miseria y desgracia de Johnny (Shklovski 127). De este modo, desde lo estructural se produce una conjunción entre forma y sentido en la nouvelle: la narración está compuesta por cuadros-coágulos que aparecen de forma inesperada, al igual que el jazz improvisado de Johnny, al igual que la muerte de Bee. Por esta razón Bruno nos dirá que "y como siempre con Johnny, las cosas han ocurrido de otra manera que la que uno esperaba" (2007: 184). La poética de Cortázar rompe con la temporalidad convencional, sorprendiendo y acercándonos a lo fantástico, a lo impredecible que desafía incluso las leyes del tiempo.

\footnotetext{
8 "Todo lo cual a mí me parecía tener una analogía muy tentadora de establecer con el surrealismo. [...] el jazz me daba a mí el equivalente surrealista en la música, esa música que no necesitaba una partitura” (Prego 229). Ver al respecto Abras Danieri (2-4).

${ }^{9}$ Bruno se presenta como un moralista, con "horror al desorden moral" (2007: 161), y sin embargo, es infiel a su mujer con Baby Lennox, adulterio al que no da importancia: "Mi mujer seguía furiosa por mi historia con Baby Lennox, nada demasiado grave por lo demás, al fin y al cabo Baby es acentuadamente promiscua y cualquier mujer inteligente debería comprender que esas cosas no comprometen el equilibrio conyugal" (2007: 201). Frente a la obsesión de Bruno por Carter, su mujer apenas aparece en el relato, y sin embargo sabemos que ha estado enferma gracias a un comentario que se produce de pasada: "Y entonces Art Boucaya ha aprovechado para darme detalles de la sesión de ayer, que me he perdido por culpa de mi mujer con neumonía” (2007: 160).
} 
Este, sin embargo, no es el único procedimiento de tipo formal que Cortázar va a esconder en su artificio narrativo. Hay que reparar en el cambio de tiempo verbal que va a introducir nuestro narrador tras acabar de relatar la conversación con Johnny en el hotel: "Pasarán quince días vacíos" (2007: 184). En un relato de acotada extensión, un mero cambio de este tipo puede suponer gran importancia (1978: 60-61). La estructura en futuro es el tiempo narrativo pertinente para que Johnny nos explique los acontecimientos siguientes, apegados a su vida cotidiana y alejados de Johnny. No por casualidad, el pretérito perfecto compuesto volverá a ser el tiempo de narración precisamente en el momento en que Johnny vuelve a encontrar a su amigo: "Mi reacción es tan natural, he querido levantar a Johnny" (2007: 187).

En el relato, Bruno tiene que ceder la voz narrativa a Johnny a través de esos coágulos para conseguir romper con la gran costumbre en la que él está anclado, en una clara oposición con la biografía escrita por el crítico, un gran éxito de ventas incapaz de ofrecer una imagen fidedigna del músico. Él mismo Johnny nos los dice: “¿Que faltan cosas, Bruno [en la biografía de Carter]? Ah, sí, te dije que faltaban cosas. Mira, no es solamente el vestido rojo de Lan" (Cortázar 2007: 195). Los monólogos de Johnny son un medio más para la búsqueda del secreto, en este caso el tiempo del pasado, que Bruno no ha plasmado en su libro sobre Carter. Por eso en El perseguidor Bruno tiene que darle la palabra a Johnny, porque el propio relato es otra forma de búsqueda su tiempo perdido. Frente a la biografía de Bruno, tan exitosa y a la vez tan fracasada, llena de huecos que no alcanzan a comprender la dimensión de la figura de Carter, la verdadera biografía del saxofonista la encontramos en El perseguidor, compuesta fragmentariamente.

Solo desde este punto de vista podemos entender a qué se refería Johnny cuando repetía al comienzo del relato "Esto lo estoy tocando mañana" (2007: 145; y de nuevo en 193), "Esto ya lo toqué mañana” (2007: 145). Johnny también utiliza el futuro, el mañana, aunque siempre de una forma hipotética, para situarse en un punto intermedio entre su tiempo absoluto y el tiempo real: "y dice Johnny que si tuviera su saxo se pasaría la noche tocando a Vivaldi" (2007: 190) o "lo que yo podría tocar ahora mismo si tuviera a los muchachos” (2007: 192). El problema es que esta opción hipotética resulta imposible, como lo es la búsqueda de Johnny del tiempo del anterior, pues el saxofonista no persigue la evasión, sino el retorno al pasado. La muerte de su hija Bee — trasunto de una verdadera hija fallecida, llamada Pree_ supone la mayor muestra de la imposibilidad de recuperación de ese tiempo, dado su carácter irreversible Johnny al final será consciente de eso: "lo que yo toco es Bee muerta" (2007: 198). La música se perfila así como el medio de "resurrección" de Bee, pues acerca al músico al tiempo anterior a su muerte.

Con la muerte de Johnny, anticipada como decíamos por el propio Bruno (2007: 162), se cierra la búsqueda un tiempo eternal, del momento detenido en el pasado literal. La voz narrativa, con uso deliberado del pretérito perfecto simple, que indica que todo ha terminado, la tiene que tomar de nuevo necesariamente Bruno, quien admite que su biografía de Carter se "sitúa en el plano meramente estético" (2007: 205). Ante la biografía académica, incapaz de sondear el verdadero misterio de la música del saxofonista, el espacio 
narrativo de El perseguidor se configura como lugar de reflexión sobre el tiempo, un tiempo libre, situado al margen de las leyes que rigen el mundo real. Este tiempo funciona como elemento cohesionador del relato, en el que Cortázar fusiona las ideas de muerte y eternidad a través del mito de Charlie Parker. De esta forma, a partir de los recursos sintácticos y narratológicos, el escritor consigue trasladar una particularidad musical (el ritmo del bebop) al campo de la literatura.

\section{OBRas Citadas}

Abras Danieri, Araceli. 2018. "El jazz y Cortázar” Álabe. Revista en red de las universidades lectoras 18: 1-18.

Borello, Rodolfo A. 1980. "Charlie Parker, el perseguidor". Cuadernos hispanoamericanos 364-366: 573-594.

Chacón, María Mercedes. 2005. "Los narradores de El perseguidor". Habladurías 2.2: 32-43.

Cifo González, Manuel. 1980. "Relativismo espacio-temporal en El perseguidor, de Julio Cortázar”. Cuadernos hispanoamericanos 364-366: 414-423.

Cortázar, Julio. 1978 [1969]. “Del cuento breve y sus alrededores”. Último Round. México: Siglo XXI. 59-93. . 2007 [1959]. Las armas secretas. Ed. Susana Jakfalvi. Madrid: Cátedra.

Coulson, Graciela. 1985. "Orfeo y el orfismo en la obra de Cortázar". Revista Chilena de Literatura 25: 101-113.

Fiddiam, Robert William. 1985. "Religious Symbolism and the Ideological Critique in 'El perseguidor' by Julio Cortázar”. Revista Canadiense de Estudios Hispánicos 9.2: 149-163.

Garí, Bernat. 2012. "La tonalidad y lo dodecafónico como estrategias tácitas de la prosa hernandiana". Cartaphilus 10: 74-83.

Goialde Palacios, Patricio. 2010. "Palabras con 'swing'. La música de jazz en la obra de Julio Cortázar”. Musiker: cuadernos de música 17: 483-496.

Jakfalvi, Susana (ed.). 2007. Julio Cortázar. Las armas secretas. Madrid: Cátedra.

Matamoros, Blas. 2002. "El músico, ese perseguidor: de Felisberto a Cortázar”. Literatura y música popular en Hispanoamérica. Eds. Ángel Esteban, Gracia Morales y Álvaro Salvador. Granada: Método. 21-28.

Oviedo, José Miguel. 1997. "Algunas reflexiones sobre el cuento y su proceso en Hispanoamérica”. El relato breve en las letras hispánicas actuales. Ed. Patrick Collard. Amsterdam: Atlanta Rodopi. 43-53.

Park, Sae-Yie. 2005. "Un encuentro a deshoras: discurso y tiempo en Deshoras, de Julio Cortázar”. Espéculo: Revista de Estudios Literarios 29. Disponible en http://www.ucm. es/info/especulo/numero29/deshoras.html [12/04/2021].

Piglia, Ricardo. 2006. "Secreto y narración. Tesis sobre la nouvelle". El arquero inmóvil. Nuevas poéticas sobre el cuento. Ed. Eduardo Becerra. Madrid: Páginas de Espuma. 187-206. 
2014. Formas breves. Madrid: Alianza.

Piqueras Flores, Manuel. 2020. La escritura musical de Felisberto Hernández: Nadie encendía las lámparas. Torino: Anejos de Artifara.

Prego, Omar. 1990. Julio Cortázar: la fascinación de las palabras. Montevideo: Trilce.

Pujals, Esteban (ed.). 2000. Dylan Thomas. Poemas. Madrid: Visor.

Stassinos, Anton Apostolos. 2007. En busca del tiempo elástico: una lectura de "El perseguidor" de Julio Cortázar. Universidad de Estocolmo [tesis de licenciatura].

Shklovsky, Viktor. 1976. "La construcción de la nouvelle y de la novela". Teoría de la literatura de los formalistas rusos. Ed. Tzvetan Todorov. Buenos Aires: Siglo XXI. 173-199.

Thomas, Dylan. 2000. Poemas. Ed. Esteban Pujals. Madrid: Visor. 
